This item was submitted to Loughborough's Research Repository by the author.

Items in Figshare are protected by copyright, with all rights reserved, unless otherwise indicated.

\title{
Variability and anisotropy of mechanical behavior of cortical bone in tension and compression
}

PLEASE CITE THE PUBLISHED VERSION

http://dx.doi.org/10.1016/j.jmbbm.2013.02.021

PUBLISHER

(C) Elsevier

VERSION

AM (Accepted Manuscript)

LICENCE

CC BY-NC-ND 4.0

REPOSITORY RECORD

Li, Simin, Emrah Demirci, and Vadim V. Silberschmidt. 2019. "Variability and Anisotropy of Mechanical Behavior of Cortical Bone in Tension and Compression". figshare. https://hdl.handle.net/2134/15574. 
This item was submitted to Loughborough's Institutional Repository (https://dspace.lboro.ac.uk/) by the author and is made available under the following Creative Commons Licence conditions.

\section{creative
commons}

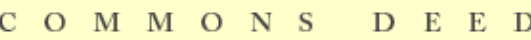

Attribution-NonCommercial-NoDerivs 2.5

You are free:

- to copy, distribute, display, and perform the work

Under the following conditions:

Attribution. You must attribute the work in the manner specified b the author or licensor.

Noncommercial. You may not use this work for commercial purposes.

No Derivative Works. You may not alter, transform, or build upon this work.

- For any reuse or distribution, you must make clear to others the license terms of this work.

- Any of these conditions can be waived if you get permission from the copyright holder.

Your fair use and other rights are in no way affected by the above.

This is a human-readable summary of the Leqal Code (the full license).

\section{Disclaimer 만}

For the full text of this licence, please go to: http://creativecommons.org/licenses/by-nc-nd/2.5/ 
Variability and anisotropy of mechanical behavior of cortical bone in tension and compression

\author{
Simin $\mathrm{Li}^{\mathrm{a}, *}$, Emrah Demirci ${ }^{\text {a, } 1}$, Vadim V. Silberschmidt ${ }^{\mathrm{a}, 2}$ \\ ${ }^{a}$ Wolfson School of Mechanical and Manufacturing Engineering, Loughborough \\ University, Loughborough, Leicestershire, LE11 3TU, UK
}

*Corresponding author. Tel.: +44 0 1509/227565; Fax: +44 0 1509/227502. Email address: S.Li@lboro.ac.uk (S. Li).

${ }^{1}$ E.Demirci@lboro.ac.uk,

².Silberschmidt@lboro.ac.uk

Key words: Cortical bone, anisotropy, variability, compression, tension, microstructure, Voigt-Reuss-Hill scheme, image process 


\begin{abstract}
The mechanical properties of cortical bone vary not only from bone to bone; they demonstrate a spatial viability even within the same bone due to its changing microstructure. They also depend considerably on different loading modes and orientations. To understand the variability and anisotropic mechanical behavior of a cortical bone tissue, specimens cut from four anatomical quadrants of bovine femurs were investigated both in tension and compression tests. The obtained experimental results revealed a highly anisotropic mechanical behavior, depending also on the loading mode (tension and compression). A compressive longitudinal loading regime resulted in the best load-bearing capacity for cortical bone, while tensile transverse loading provided significantly poorer results. The distinctive stress-strain curves obtained for tension and compression demonstrated various damage mechanisms associated with different loading modes. The variability of mechanical properties for different cortices was evaluated with two-way ANOVA analyses. Statistical significances were found among different quadrants for the Young's modulus. The results of microstructure analysis of the entire transverse cross section of a cortical bone also confirmed variations of volume fractions of constituents at microscopic level between anatomic quadrants: microstructure of the anterior quadrant was dominated by plexiform bone, whereas secondary osteons were prominent in the posterior quadrant. The effective Young's modulus predicted using the modified Voigt-Reuss-Hill averaging scheme accurately reproduced our experimental results, corroborating additionally a strong effect of random and heterogeneous microstructure on variation of mechanical properties in cortical bone.
\end{abstract}




\section{Introduction}

A random (i.e. non-periodical) and hierarchical microstructure of bone material has for decades attracted many researches to investigate its mechanical behavior. As a natural composite material, cortical bone mainly consists of type I collagen with imbedded mineral phase and water (Rho et al., 1998). As a result of its formation, this anisotropic structure leads to some very interesting mechanical behaviors, such as anisotropy of its mechanical properties with regard to its main directions: longitudinal (parallel to the main axis of a bone) and transverse (perpendicular to it). This orientation dependency has been well studied in a number of experiments at either macro-scale (Reilly and Burstein, 1975; Zioupos et al., 1995) or micro-scale (Rho et al., 1997) conducted by means of mechanical or non-mechanical techniques (Ashman et al., 1984; Lawrence et al., 1984). Bonfield and Grynpas (1977) developed an ultrasonic method to measure the effect of orientation on elastic properties by varying the angle of specimen from $0^{\circ}$ to $90^{\circ}$. A maximum ratio of two was reported between $0^{\circ}$ (longitudinal) and $90^{\circ}$ (transverse); this ratio changes for different loading modes. Reilly and Burstein (1975) reported a reduction in the anisotropic ratio for the elastic modulus measured in compression. In the same work, they also noticed dissimilar mechanical properties in tension and compression. The compressive ultimate strength of bovine cortical bone in transverse direction was reported to be nearly three times than that in tension. Much higher ultimate stress and strain levels in compression indicate realization of different deformation mechanisms at different loading conditions (Mercer et al., 2006; Nyman et al., 2009). Despite the significant difference, only limited knowledge is available about the mechanical properties in compression. It can be partially explained by the fact that it is generally easier to perform a test in tension or bending rather than in compression (Currey, 2011). Another reason is a complex character of failure in compression: unlike tension, where failure occurs as soon as the material's strength is attained, a bone specimen in compression can still carry load even after severe deformation (Currey, 2011). Reilly and Burstein (1974) pointed out in their work that shear mechanism acted under compression. Mercer and his co-authors (2006) further studied the damage mechanism under compression and suggested a possible slippage interaction between collagen and mineral phase causing the irreversible deformation. Nyman et al. (2009) compared damage mechanisms for both tension and compression in their work where they 
found a diffuse damage pattern in tension, while a less hazardous crosshatch type of damage in compression, which allows more energy to dissipate, was observed.

Unlike other engineering materials, the material properties of cortical bone cover a wide range of values linked to many factors such as dissimilarity of animal species, age, gender and etc. and testing techniques that employed (Rho et al., 1998). A brief literature survey demonstrates that for bovine femur tested in longitudinal direction at low strain rate, the Young's modulus ranges from 8.5 GPa to 24.5 GPa (Reilly and Burstein, 1974). The ultimate stress and strain for the same condition ranges from $219 \mathrm{MPa}$ to $283 \mathrm{MPa}$ and $1.6 \%$ to 3.3\%, respectively (Reilly and Burstein, 1975; 1974). Currey (2004) in his recent work described this variability as incompatible mechanical properties. A list of mechanical properties for "normal" bone as presented in the same work with extreme cases. So, what exactly these ranges of data tell us? And values should one choose for finite-element (FE) simulations when studying the mechanical behavior, e.g., in sport injury analysis? The answer should be sought at microstructural level.

Apart from the variations due to origin, age, health state and some other secondary factors, the variability of mechanical properties exists even at the level of individual bone. Independent work done by Su et al. (1999), Lai et al. (2005), Skedros et al., (1994), Abdel-Wahab et al. (2010) and Li et al. (2012a and b) confirmed a correlation between mechanical properties and local anatomic position for both artiodactyl and human bone. The reasons for this correlation defined as the effect of mineral content (Lai et al., 2005; Skedros et al., 1997); adaptive transition of microstructure (Riggs et al., 1993a); prevalence of specific strain or local motion (Su et al., 1999). However, there is still a lack of quantification of the causes for the observed variability in the literature.

The effect of microstructure has always been an important focus point in the research area (O'Brien et al., 2005). At micro-scale level, there are mainly three types of bone found in large vertebrates animals (Martin et al., 1998; Ritchie et al., 2005): (i) plexiform (or fibrolamellar) bone is formed more rapidly to allow a fast increase in the load-bearing capacity; (ii) osteonal bone (including primary and secondary osteons) consists of concentric lamellae structures hollowed by a vessel channel or a haversian canal depending on the type of osteon; (iii) interstitial bone is usually the remaining structure surrounding the osteonal bone. Due to different formation periods and methods, the mechanical behaviors of individual constituents vary slightly. Earlier attempts to predict the bone's effective elastic modulus were 
more concentrated on the influence of individual constituents such as osteon, mineral contents, density and porosity etc. or feature on the overall elastic properties (Currey, 1988a; Saha and Hayes, 1977). More advanced models, accounting for shape and orientation effects of individual constituents (Currey, 1984; Sevostianov and Kachanov, 2000) as well as the interaction between collagen and mineral contents (Chen et al., 2009) were reported. Despite this variety, most have one common feature: all the approaches were related to a fundamental concept of the theory of composite materials - the rule of mixture.

Sevostianov and Kachanov (2000) calculated the elastic modulus using a modified formula that is commonly employed for high-elastic-contrast composite-like materials and achieved good agreement. On the other hand, McKittrick and coauthors (Chen et al., 2009; Novitskaya et al., 2011) calculated the effective elastic modulus using a modified Voigt scheme for both elk antlers and bovine cortical bone. However, their results showed a large disparity with the experimental data. Then, they further suggested that the effective elastic constant of cortical bone is a complex combination effect of individual constituents in terms of orientation, shape, volume fraction and their interactions at several hierarchy levels.

Some recent studies (Fritsch and Hellmich, 2007; Hamed et al., 2010) proposed a comprehensive approach that involved a multi-scale realization to estimate an effective elastic constant by constructing the stiffness tensor for each constituent at multiple levels using a Mori-Tanaka scheme based on micromechanics and structural arrangement. Their model indeed provided a better understanding of the influence of each constituent at various levels. However, the problem of local variability and widely ranged mechanical properties of cortical bone in the literature still remains unsolved.

The aim of this study is to provide a comprehensive comparison of the anisotropy and variability of mechanical properties of bovine cortical bone under both tension and compression. The main focus is on the microstructure-related variability that is characteristic even for a single bone; other types of variability - caused, for instance by different age, health state, nutrition etc. - are outside the remit of this study. To the authors' knowledge, currently, there is no single source in the literature that provides a full comparison of mechanical properties of bovine cortical bone both for different loading conditions and orientations. Therefore, the first part of this study is aimed at evaluation of various mechanical properties and their comparison. The second part of the study is focused on the variability at 
different cortices and the correlations between the mechanical properties and underpinning microstructures.

\section{Material and methods}

\subsection{Specimen preparation}

Two fresh bovine femurs were obtained from a local butchery shop from the same animal about 1.5 to 2 years old. Soft tissue and bone marrow were removed and the femurs were thoroughly cleaned using cold -water. Initially, the femurs were excised into rectangular-shaped samples according to four anatomic quadrants (Anterior, Medial, Posterior and Lateral) (see Fig. 1) within the mid-diaphysis using a low-speed band saw and then with a diamond blade (Isomet Low-Speed Saw, Buehler). The specimens were cut for two orientations: longitudinal (parallel to the main axial of the femur) and transverse (perpendicular to it). They were then polished using a Grinder-Polisher (Buehler) with series of ANSI silicon carbide paper - 240, 600 and 1200- to improve surface finish and eliminate surface damage induced during the cutting process. After that, the specimens were divided into two groups for different tests - tension and compression. For a tension test, the specimens were further machined into dumb-bell shape $(15 \mathrm{~mm} \times 5 \mathrm{~mm} \times 2 \mathrm{~mm}$ in gauge length) (Abdel-Wahab et al., 2010) using a diamond blade and milling machine. For a compression test, a precise lathe and drilling machine were used to turn the rectangular specimens into cylindrical shape specimens (Ø5 mm $\times 5 \mathrm{~mm}$ ). All specimens for testing were finally polished with fine polishing cloth with diamond-dust suspension. All cutting procedures were kept under continuous water irrigation to avoid specimen's dehydration and temperature rise. A total of over 100 specimens were acquired for both tension and compression tests and were stored in $0.9 \%$ saline solution at room temperature priory to test. All mechanical experiments were finished within 72 hours after sample preparation. 


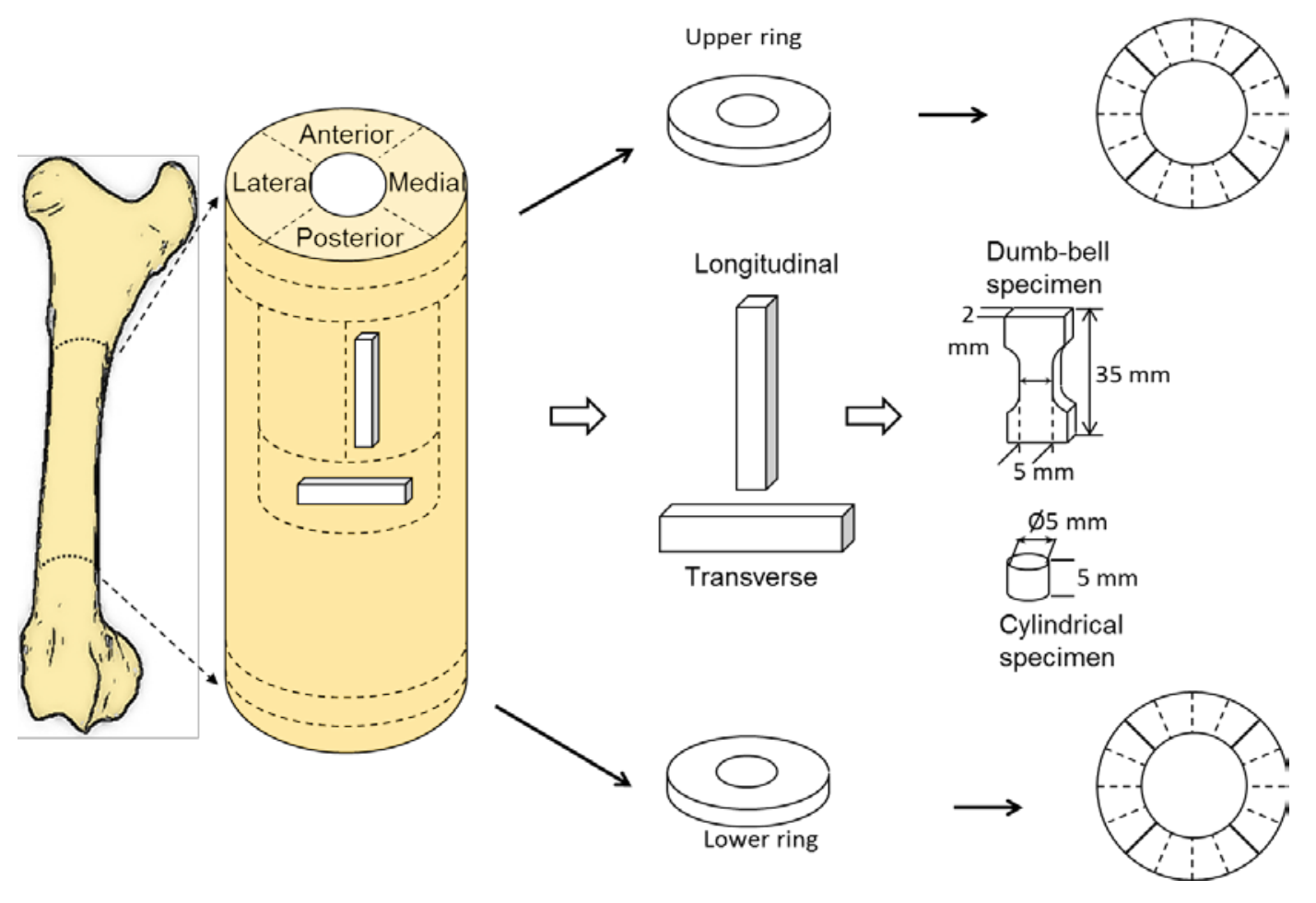

Fig. 1 Schematic illustration of specimen preparation process

\subsection{Tension and compression tests}

Both uniaxial tensile and compressive tests were conducted using a universal testing machine (Instron 3366 bench-top dual column system) with a $10 \mathrm{kN}$ load cell. Each type of test was performed for four different quadrants in both longitudinal and transverse directions. The specimens were selected to maximize the equal distribution across the femur cross-section for a more accurate representation of population. 7 tests were conducted for each position. Each specimen was loaded under displacement control until failure at a strain rate of $1 \times$ $10^{-3} \mathrm{~s}^{-1}$. The level of displacement was measured using a $10 \mathrm{~mm}$ gage length extensometer (2630 Series, Instron) and a LVDT sensor with a travel length of \pm 2.5 mm (2601 Series, Instron), respectively in tensile tests and compressive tests. Experiments were carried out at ambient room temperature and specimens were kept hydrated using saline spray. A thin layer of lubricant was applied to the contact surfaces between end-plates and specimens prior to compression test to reduce the frictional end effect. The Young's modulus was determined using the average tangential modulus of the initial slope of the stress-strain curve. The yield point was determined by means of traditional $0.2 \%$ strain offset. 


\subsection{Microstructure analysis}

To quantify the variation of microstructure across the cross-section of bovine femur, two cross-section rings from the top and bottom of the mid-diaphysis of one femur were excised (see Fig. 1), polished and analyzed with optical microscopy (Olympus BX60M). 16 tiling images were taken for each ring section and then analyzed using Image-Pro software (Image-Pro 7.0, Media Cybernetics). The images were evenly distributed across the ring (four images for one cortex) and each image consisted of a series of tiling images across the thickness (radius direction) of cortical bone. The microstructure analysis was carried out by distinguishing the following constituents: osteons (including both primary and secondary osteons), plexiform, interstitial and porosity areas. The following procedure was implemented to calculate the fraction area of each part:

1. The image was trimmed to remove dark edges and then porosity was calculated by counting the remaining dark spots of the image.

2. The plexiform area was calculated first by drawing the outline of the corresponding region and then subtracting the porosity area and areas of other structures from the region.

3. The osteonal area was calculated by capturing the outline of individual osteons (excluding the Haversian canal areas) and summing up inputs from individual osteons. The procedure to distinguish the osteonal bone was based on the criteria employed by Saha and Hayes (1977).

4. The interstitial area was calculated as the area of the remaining part.

The method used to capture the irregular shapes of microstructure employed a combination of image processing techniques and image auto-recognition features to increase the contrast of the border line between constituents. However, manual adjustment was still required to compensate for deficiencies of the computer algorithm. The fraction area was calculated using a pixel-based planimetry measuring technique. The boundaries between primary osteons and interstitial area as well as plexiform to interstitial interface are not easy to distinguish. Occasionally, the border line between them was not clear. As a result, the reproducibility of the measurement using this method was tested to be within $\pm 4 \%$. 
Using a modified Voigt-Reuss-Hill (VRH) averaging scheme based on (Bonfield and Clark, 1973; Carter and Hayes, 1977), the effective Young’s modulus was calculated according to the following equation:

$E_{\text {total }}=\left(E_{\mathrm{O}} \times V_{\mathrm{O}}+E_{\mathrm{I}} \times V_{\mathrm{I}}+E_{\mathrm{P}} \times V_{\mathrm{P}}\right) \times(1-p)^{3}$.

The subscripts $\mathrm{O}$, I and P denote osteonal, interstitial and plexiform areas, respectively; $E$ and $V$ represent the Young's modulus and volumetric fraction of respective parts; $p$ is the percentage of porosity. The Young's moduli used in the calculation are listed in Table 1.

Table 1 Magnitudes of Young's modulus used in the calculations based on Equation 1

\begin{tabular}{cccc}
\hline & Osteonal & Interstitial & Plexiform \\
\hline Longitudinal & $22.7^{\mathrm{a}}$ & $25.1^{\mathrm{b}}$ & $26.5^{\mathrm{a}}$ \\
Transverse & $12.85^{\mathrm{c}}$ & $14.12^{\mathrm{d}}$ & $15.67^{\mathrm{c}}$
\end{tabular}

(a. (Reilly and Burstein, 1975) ; b. (Rho and Pharr, 1999); c. (Lawrence et al., 1984); d. (Budyn and Hoc, 2007))

\subsection{Statistical analysis}

For a more robust comparison of various properties for tension and compression as well as for different cortices, two types of statistical analysis were carried out. The Weibull survival analysis (Weibull, 1951) was conducted to analyze the probability distributions of the evens when failure is likely happened. The Weibull distribution function is given as:

$F(x, b, m)=1-\exp \left(-\left(\frac{x}{b}\right)^{m}\right)$

where $b$ and $m$ are the scale and shape parameters of the distribution function. $m$ is also called the Weibull modulus, which determines the variability of a given distribution. $x=b$ is the characteristic corresponding to $63.21 \%$ of the specimens being failed according to (Weibull, 1951).

ANOVA (analysis of variance) analysis was also carried out to validate the significant differences between each tested groups. Since the tests were designed 
with regard to two variables: individual cortices (Factor A) as well as loading modes (Factor B), two-way ANOVA analyses were performed at a significance level $(\alpha)$ of 0.05 . Shapiro-Wilk normality tests were conducted prior to each analysis to verify a normal distribution of testing group. The variances between testing groups were further investigated using the Tukey HSD multiple comparison test. The null hypotheses for each of the sets are: the means of testing samples grouped by each factor are the same; the two factors are independent variables with no interaction. The significant difference is reported by rejecting the null hypothesis when the p-value (the probability value of obtaining a test statistics at extreme cases where null hypothesis is true) is smaller than the $\alpha$ value.

\section{Results and analysis}

\subsection{Stress-strain relations in tension and compression}

The mechanical behavior of cortical bone in response to different loading conditions diverged dramatically (Tab. 2 and Figs. 2 and 3), both in terms of stressstrain relation and damage mechanism.

Table 2 Average and standard deviation of mechanical properties of bovine cortical bone for four cortices (anterior, medial, posterior and lateral) at different loading conditions

\begin{tabular}{|c|c|c|c|c|c|c|}
\hline Orientation & $\begin{array}{c}\text { Loading } \\
\text { type }\end{array}$ & $\begin{array}{c}E \\
(\mathrm{GPa})\end{array}$ & $\begin{array}{c}\sigma_{\mathrm{y}} \\
(\mathbf{M P a})\end{array}$ & $\begin{array}{c}\varepsilon_{\mathrm{y}} \\
(\%)\end{array}$ & $\begin{array}{c}\sigma_{\mathrm{u}} \\
(\mathrm{MPa})\end{array}$ & $\begin{array}{c}\varepsilon_{u} \\
(\%)\end{array}$ \\
\hline \multirow{5}{*}{ Longitudinal } & \multirow{2}{*}{ Compression } & 19.09 & 184.62 & 1.20 & 214.39 & 2.37 \\
\hline & & \pm 2.84 & \pm 22.51 & \pm 0.09 & \pm 27.57 & \pm 0.38 \\
\hline & \multirow{3}{*}{ Tension } & & & & & \\
\hline & & 20.22 & 75.85 & 0.61 & 97.41 & 1.85 \\
\hline & & \pm 3.12 & \pm 13.98 & \pm 0.11 & \pm 19.88 & \pm 0.39 \\
\hline \multirow{5}{*}{ Transverse } & \multirow{2}{*}{ Compression } & 11.62 & 112.78 & 1.06 & 131.16 & 2.40 \\
\hline & & \pm 2.4 & \pm 19.61 & \pm 0.21 & \pm 22.02 & \pm 0.73 \\
\hline & & & & & & \\
\hline & \multirow[t]{2}{*}{ Tension } & 12.43 & 32.92 & 0.27 & 40.18 & 0.54 \\
\hline & & \pm 2.37 & \pm 7.85 & \pm 0.09 & \pm 9 & \pm 0.18 \\
\hline
\end{tabular}

At the initial elastic region, similar linear stress-strain relationships were observed for both loading modes. The averaged elastic modulus $\mathrm{E}$ in tension and 
compression were found to be $20.22 \pm 3.12 \mathrm{GPa}$ and $19.09 \pm 2.84 \mathrm{GPa}$ for longitudinal, $12.43 \pm 2.37 \mathrm{GPa}$ and $11.62 \pm 2.4 \mathrm{GPa}$ for transverse, respectively. The results are compatible with those reported in previous literature (Reilly and Burstein, 1975). Although, there was a difference of some 6\% between the tension and compression moduli, statistical analysis discussed below revealed a detailed significant level across all testing groups, and the results were not consistent for longitudinal and transverse directions. A small toe region (a non-linear initial portion of the stress-strain curve) that appeared at the beginning of the deformation process was also observed in other studies (Currey, 1988b; Kotha and Guzelsu, 2003; Novitskaya et al., 2011) that employed different testing configurations. The results suggest that this initial deformation process might be evoked by the native deformation mechanisms across multiple levels, such as stretching and sliding at interfaces due to the weak bond and opening/closure of voids and porous space.

Beyond the elastic region, the divergence starts. Tensile specimens sustain much lower deformation and stress than compressive specimens. Yield happens at a relative early stage. A bi-linear stress-strain relationship was observed in both longitudinal and transverse orientations (Abdel-Wahab et al., 2010). However, in compression, yield commences at a much higher stress. The average levels of yield stress $\sigma_{\mathrm{y}}$ and strain $\varepsilon_{\mathrm{y}}$ were $184.62 \pm 22.51 \mathrm{MPa}$ and $1.20 \% \pm 0.09 \%$ for longitudinal, $112.78 \pm 19.61 \mathrm{MPa}$ and $1.06 \% \pm 0.21 \%$ for transverse, respectively. That was more than two times higher than for tension both in terms of yield stress and yield strain. The representative post-yield stress-strain curves from anterior quadrant for both tension and compression are shown in Figs. 2 and 3. In tension, the flow stress-strain curves between individual specimens are much closer to each other (shaded area) and comparable (similar tangential modulus). Failure in tension occurs as soon as the damage starts, whereas in compression, damage propagation is a relatively slow process and is inhibited by the compressive state, therefore, combining both the damage softening and strain hardening effects. As a result, the flow curves in compression are more spread out and their tangential moduli vary significantly. 


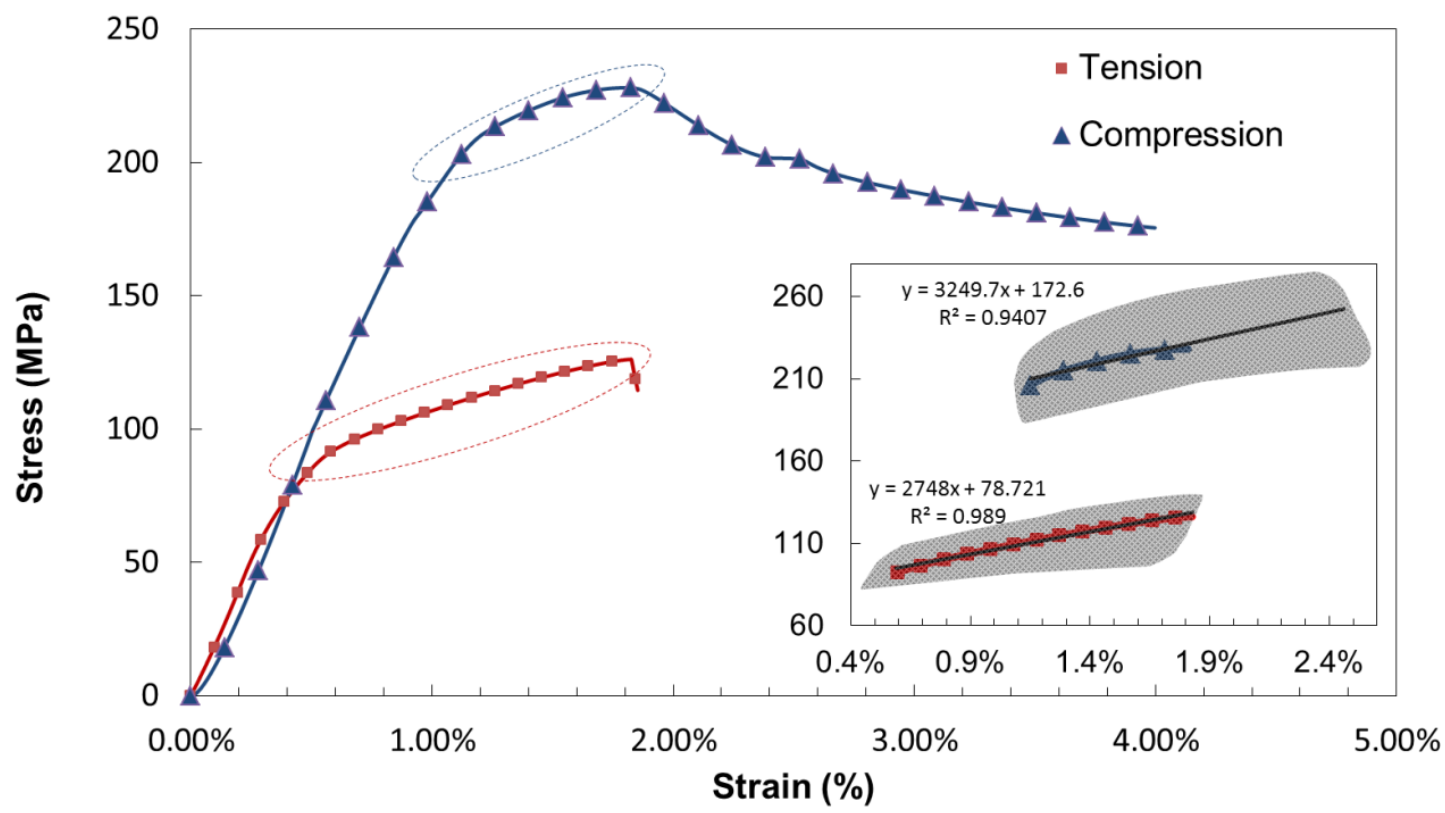

Fig. 2 Typical stress-strain curves for longitudinal specimen in tension and compression (anterior quadrant). Inserts show strengthening portions

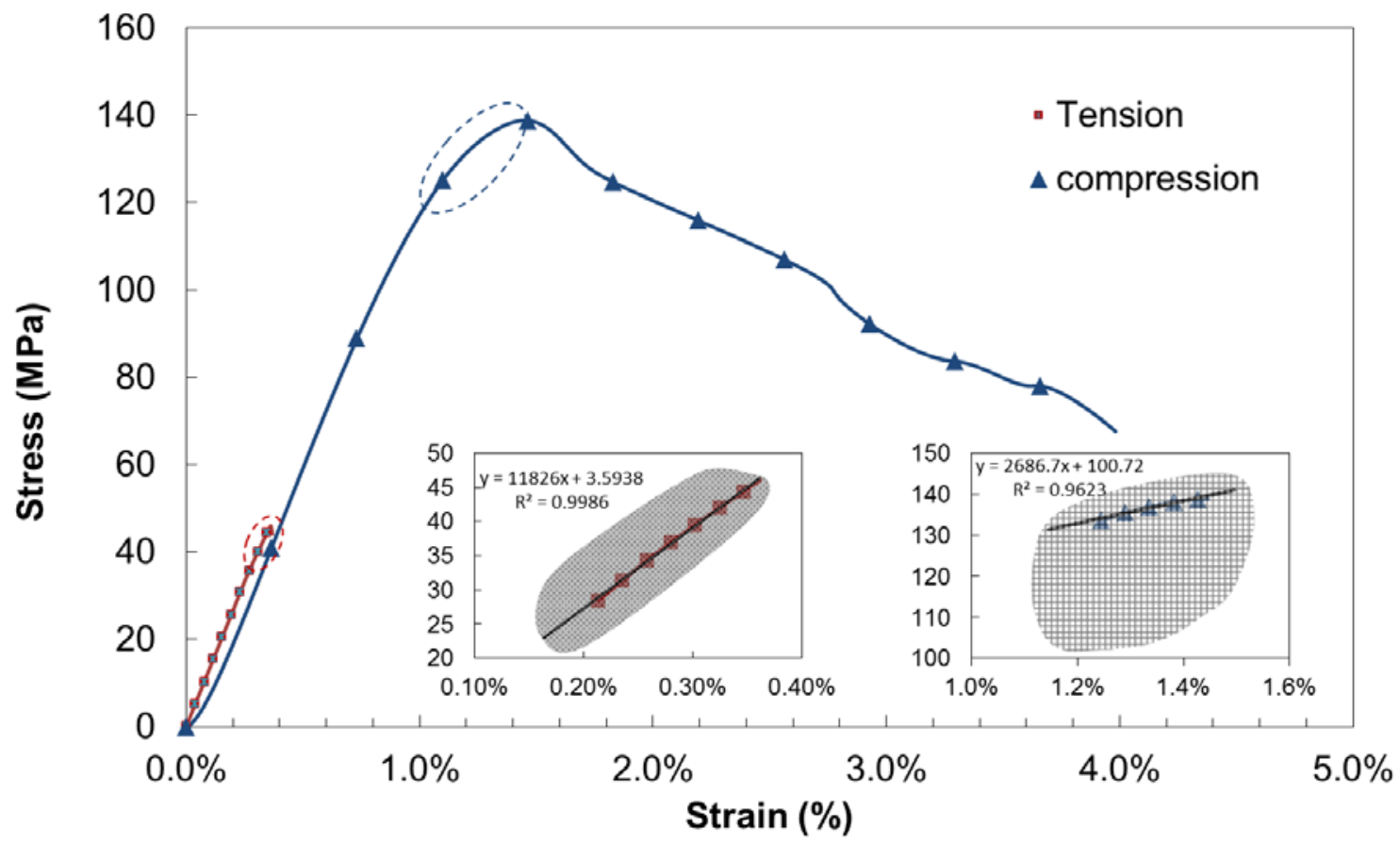

Fig. 3 Typical stress-strain curves for transverse specimen in tension and compression (anterior quadrant). Inserts show strengthening portions 
After reaching to the maximum stress $\sigma_{\mathrm{u}}$, the damage mechanism becomes dominant and material start disintegrating and losing its load bearing capacity. However, the failure occurred in rather different ways. In tension, cortical bone fails in a brittle manner just after the stress-strain curves passing the ultimate point (George and Vashishth, 2005). On the contrary, due to the shear damage mechanism observed in compression (Fig. 4), the character of stress-strain curve is determined by the combined effects of local stress hardening and shear sliding. Higher local stress hardening and lower shear sliding lead to steeper stress-strain curves. Generally, there are three types of stress-strain relations as shown in Fig. 4: (i) a sudden reduction of stress at lower strain when normally a major fracture throughout the specimen occurs (Fig. 4-a); (ii) flat progression is usually accompanied with multiple fractures (Fig. 4-b); (iii) a continuous reduction corresponds to an intermediate case between the previous two, with several cracks progressively propagating through the specimen (Fig. 4-c). As a result, failure in compression is less predictable and could happen well before reaching the average ultimate stress. With data recording up to $6 \%$ of strain, the maximum stress reduction observed during the experiments was about 50\% and $60 \%$ in longitudinal and transverse direction, respectively.

Figure 5 demonstrates the likelihood failure regions of cortical bone specimen for different loading conditions, determined by positions of the ultimate stress. In general, compressive specimens have larger failure regions compared to tensile specimens, especially for the transverse orientation, where resistance to shear sliding is significantly lower due to the microstructural alignment. The Weibull distribution revealed the probability distribution of failure in terms of ultimate stress (Fig. 6-a) and ultimate strain (Fig. 6-b). As obvious from Fig. 6-a, distributions of failure strengths have no overlaps, while the distributions of failure strains for specimens in compression have overlapping ranges. Although, the mean ultimate strain for compressive transverse specimens is similar to that for the longitudinal direction; a lower Weibull modulus (3.85 compared to 7.17) indicates a less reliability at the transverse direction, which means that the specimens are more likely to fail at lower strain (Fig. 6-b). 


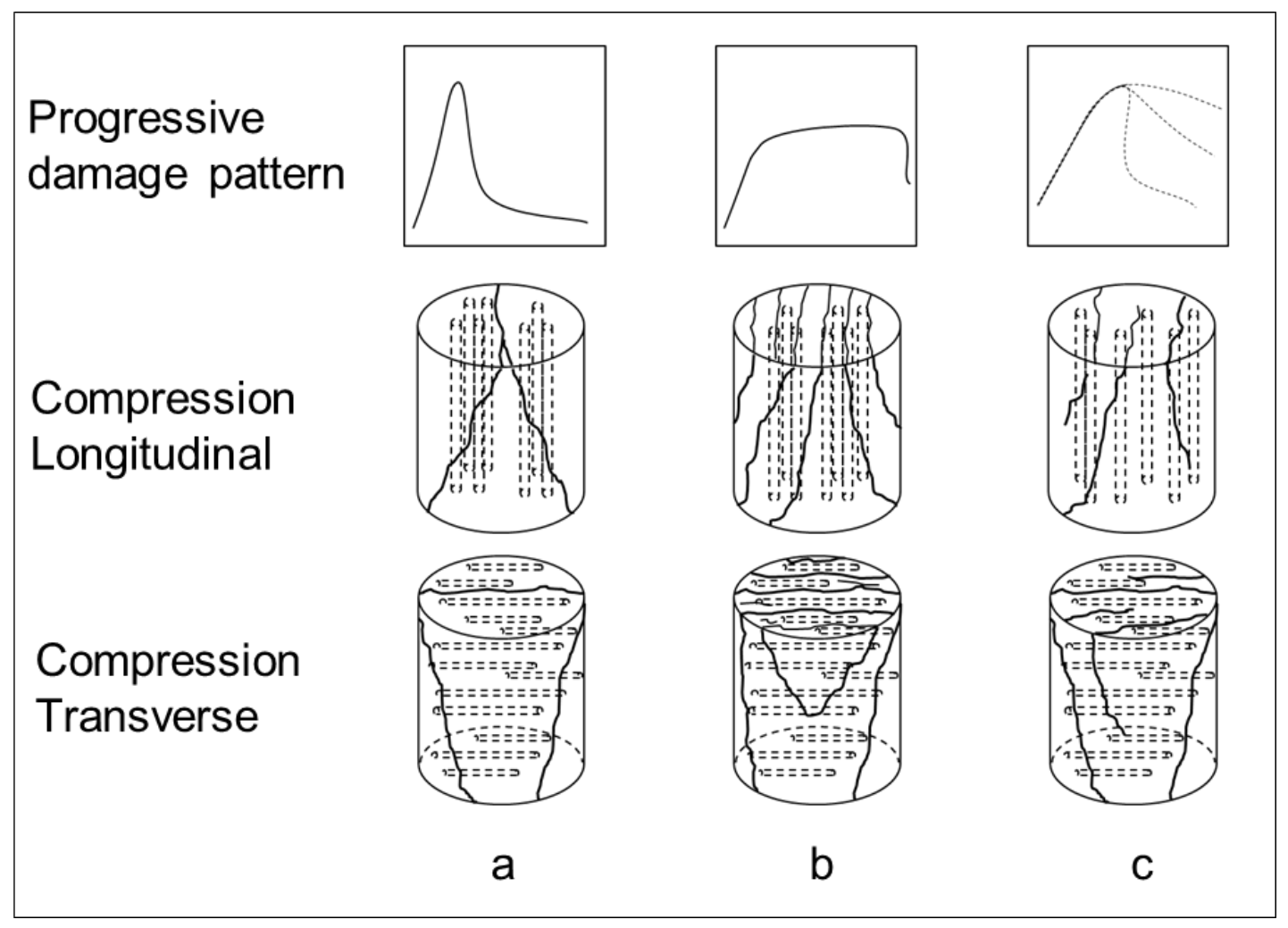

Fig. 4 Schematic illustration of different progressive damage behaviors for compressive loading (first row represents character of stress-strain curves, second and third lines represent typical damage patterns with regard to osteons (shown with dashed line) 


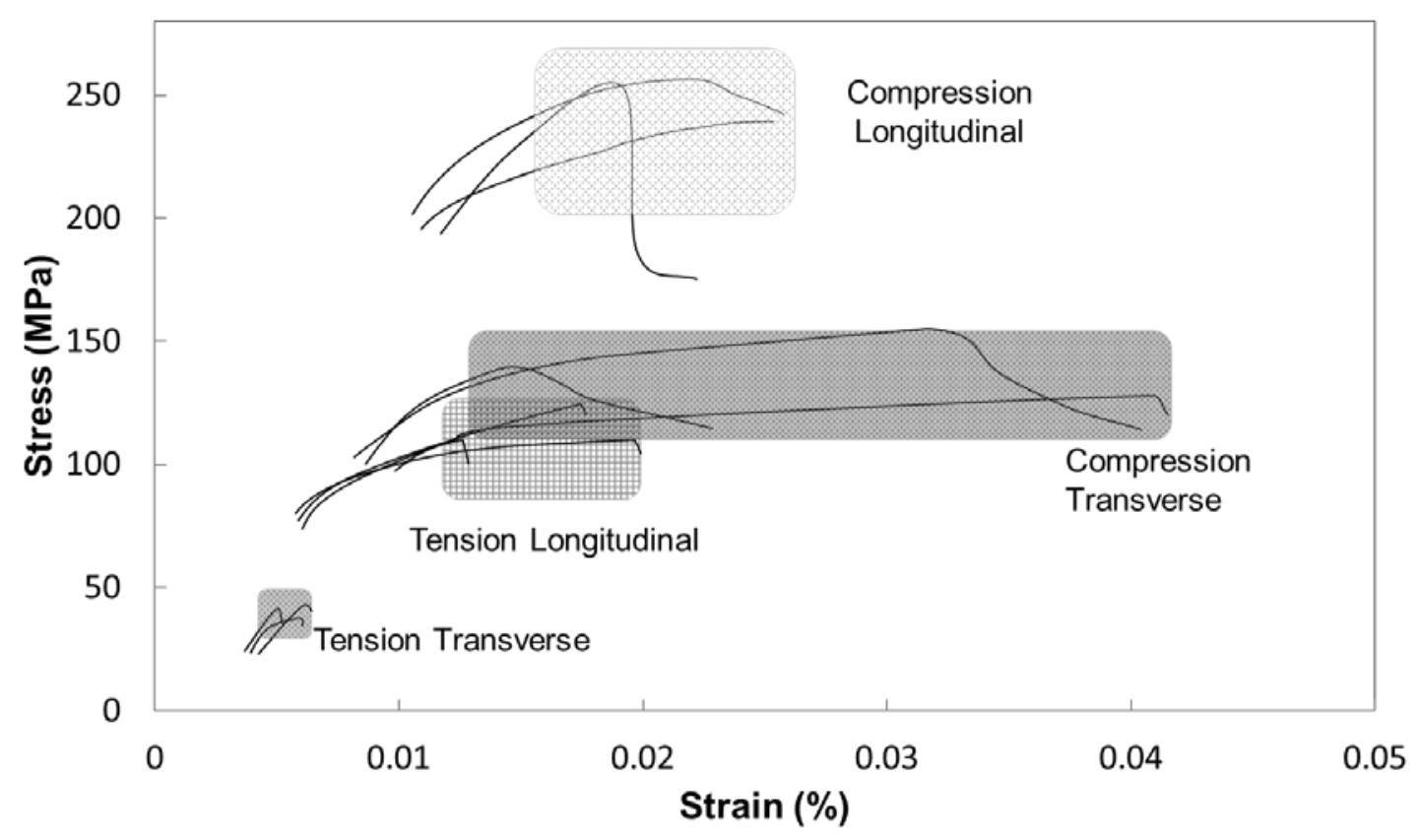

Fig. 5 Representative failure regions determined by ultimate stress levels (anterior quadrant)

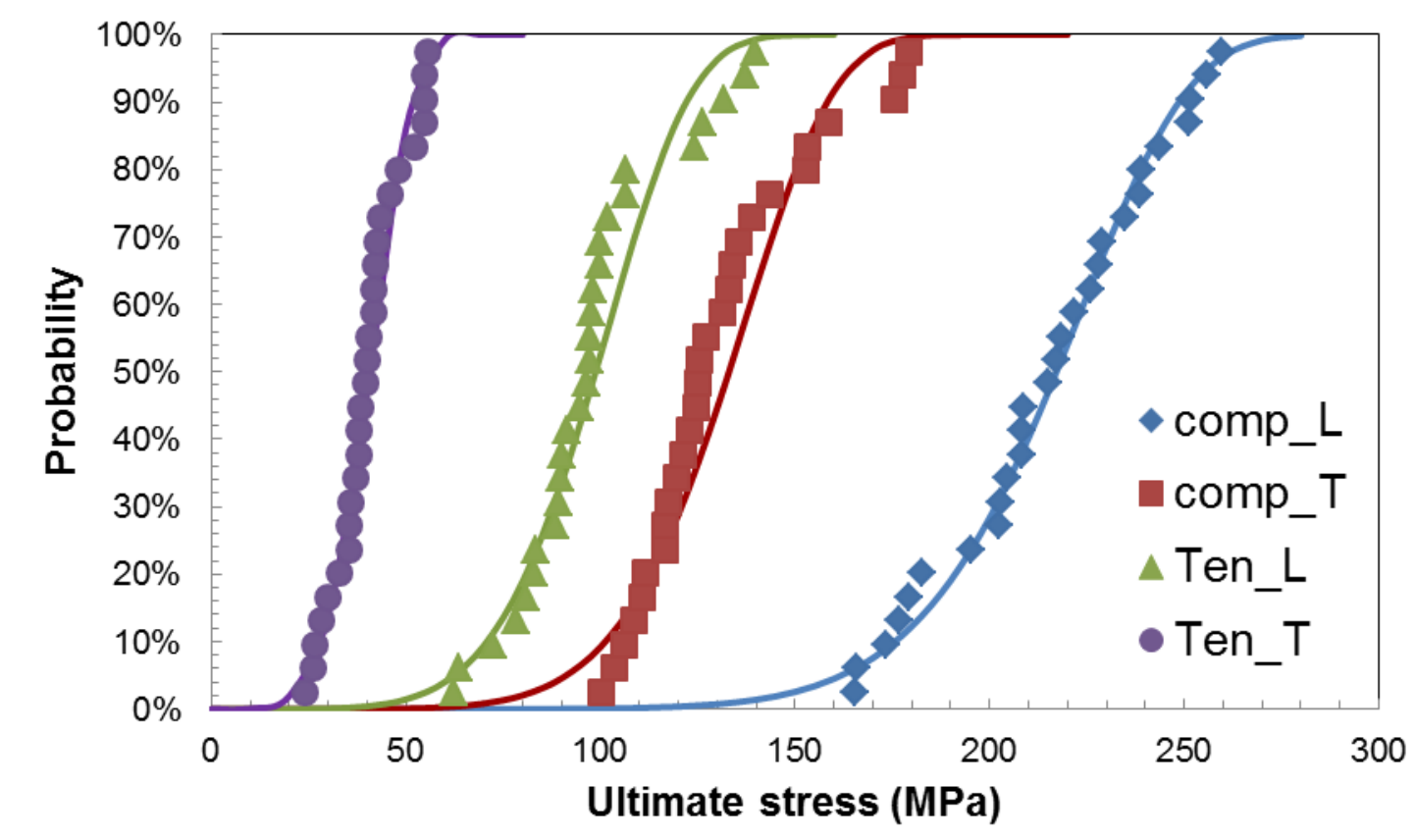

Fig. 6a Weibull probability distribution plots for ultimate stress (a) and ultimate strain (b) (number of specimens=28, comp: compression; ten: tension; L:

longitudinal; T: transverse) 


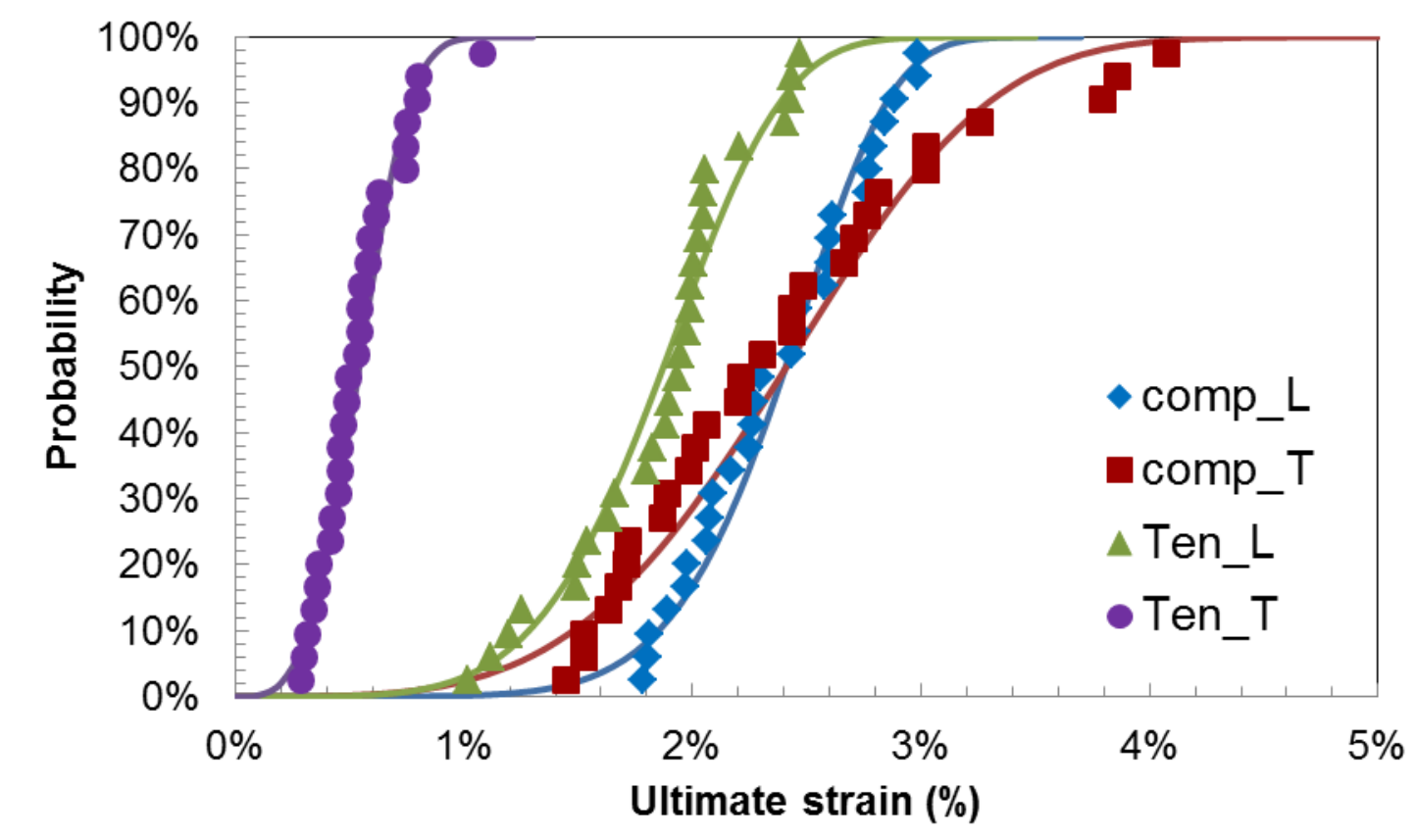

Fig. 6b Weibull probability distribution plots for ultimate stress (a) and ultimate strain (b) (n number of specimens =28, comp: compression; ten: tension; L: longitudinal; T: transverse)

\subsection{Orientation anisotropy}

The diverged mechanical behaviors were also observed with respect to orientation (Fig. 7). Transverse specimens loaded in tension appear to be very brittle and fail at much lower strains compared to the longitudinal direction, but the difference for compression is less prominent. Regardless of the loading mode, specimens loaded in longitudinal direction always demonstrate a higher stiffness (higher Young's modulus) and strength (higher ultimate stress) than those in the transverse direction. An anisotropic ratio is introduced here as the parametrical ratio of material properties obtained for the longitudinal and transverse orientations. The summarized data are shown in Table 3. The ratio for the Young's modulus ranges from 1.47 to 1.79; this closely agrees with the previous research (Abdel-Wahab et al., 2010). Generally, the stress ratios (yield and ultimate) in tension (over 2) are higher than in compression (1 to 2). Still, the strain ratios are quite different for different loading modes. In tension, the yield- and ultimate-strain ratios are in the range from 2 to 4 , but in compression, they are almost orientation independent (i.e. nearly isotropic). 


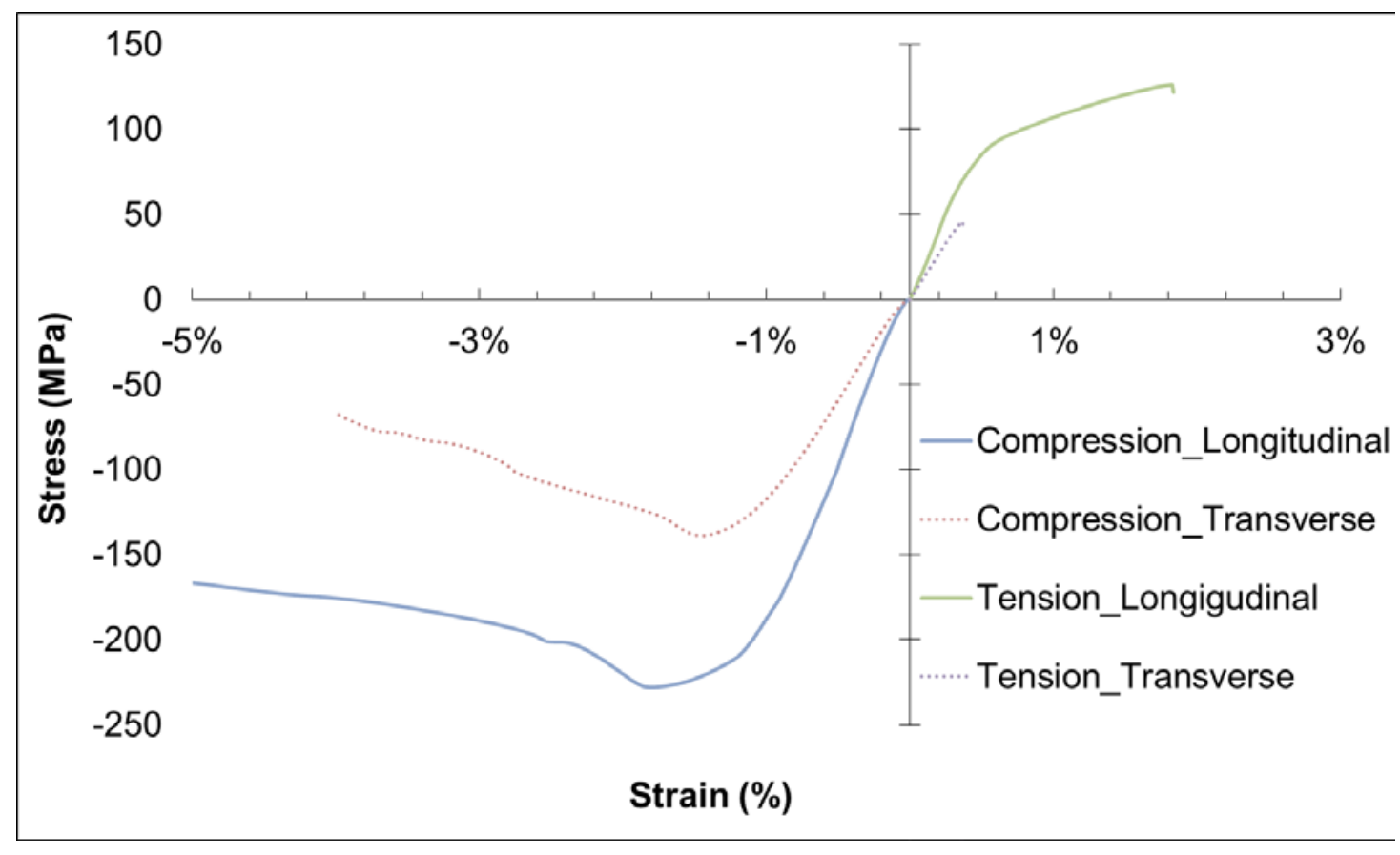

Fig. 7 Stress-strain curves for different loading conditions for longitudinal and transverse directions

Table 3 Anisotropic ratio for both tension and compression for various anatomic quadrants ( $\mathrm{T}$ and $\mathrm{C}$ represent tension and compression, respectively)

\begin{tabular}{ccc|cc|cc|cc|cc}
\hline \multirow{2}{*}{$\begin{array}{c}\text { Anisotropic } \\
\text { ratio }\end{array}$} & \multicolumn{2}{c|}{$\begin{array}{c}\text { Young's } \\
\text { Modulus }\end{array}$} & \multicolumn{2}{c|}{ Yield stress } & \multicolumn{2}{c|}{ Yield strain } & \multicolumn{2}{c|}{$\begin{array}{c}\text { Ultimate } \\
\text { stress }\end{array}$} & \multicolumn{2}{|c}{$\begin{array}{c}\text { Ultimate } \\
\text { strain }\end{array}$} \\
\cline { 2 - 12 } & $\mathrm{T}$ & $\mathrm{C}$ & $\mathrm{T}$ & $\mathrm{C}$ & $\mathrm{T}$ & $\mathrm{C}$ & $\mathrm{T}$ & $\mathrm{C}$ & $\mathrm{T}$ & $\mathrm{C}$ \\
\hline Anterior & 1.73 & 1.70 & 2.69 & 1.69 & 2.33 & $\mathbf{1 . 3 0}$ & 2.65 & 1.64 & 4.02 & $\mathbf{0 . 7 2}$ \\
Medial & 1.52 & 1.47 & 2.10 & 1.51 & 2.48 & $\mathbf{1 . 0 5}$ & 2.19 & 1.60 & 3.11 & $\mathbf{1 . 0 4}$ \\
Posterior & 1.76 & 1.79 & 2.58 & 1.83 & 2.52 & $\mathbf{1 . 0 6}$ & 2.77 & 1.81 & 3.73 & $\mathbf{1 . 1 2}$ \\
Lateral & 1.52 & 1.65 & 2.11 & 1.52 & 1.82 & $\mathbf{0 . 9 6}$ & 2.12 & 1.50 & 2.97 & $\mathbf{1 . 1 7}$ \\
\hline
\end{tabular}

\subsection{Variability of cortical bone and statistical analysis}

Asymmetric material properties from both tension and compression experiments for four anatomic quadrants (cortices) are illustrated in Fig. 8. Apparently, the anterior quadrant has the highest young's modulus in longitudinal direction, while, the medial quadrant was the highest one in transverse direction. The lowest values were for lateral and posterior quadrants for longitudinal and transverse directions, respectively. The difference between the highest to the lowest values of the 
Young's modulus was around 5 GPa in longitudinal and 4 GPa in transverse orientations. The relations across different quadrants were compared in terms of significance of variances using the two-way ANOVA analysis. Though the results showed a statistical significance for factor A (between cortices), the significance level for factor B (between loading modes) did not result in a unified conclusion. The interaction between the two factors appeared to be negative, which means that loading modes do not have effective contribution to the variability across cortices and vice versa. Detailed Tukey HSD tests together with pairwise comparisons between factors are summarized in Table 4. According to the statistical analysis, no significant variances were found between anterior to medial and posterior to lateral quadrants in all analysis, which suggests a strong linkage between each of the two pairs. On the other hand, the differences between the opposite quadrants were consistently significant ( $<0.05$ for all comparisons), where the dissimilar microstructures were also observed according to microstructure analysis that is discussed below. Less-consistent values were found between anterior to lateral and medial to posterior quadrants, where the transition of the microstructure happened to be the most severe. A schematic illustration of the significant difference between the four cortices is presented in Fig. 9.

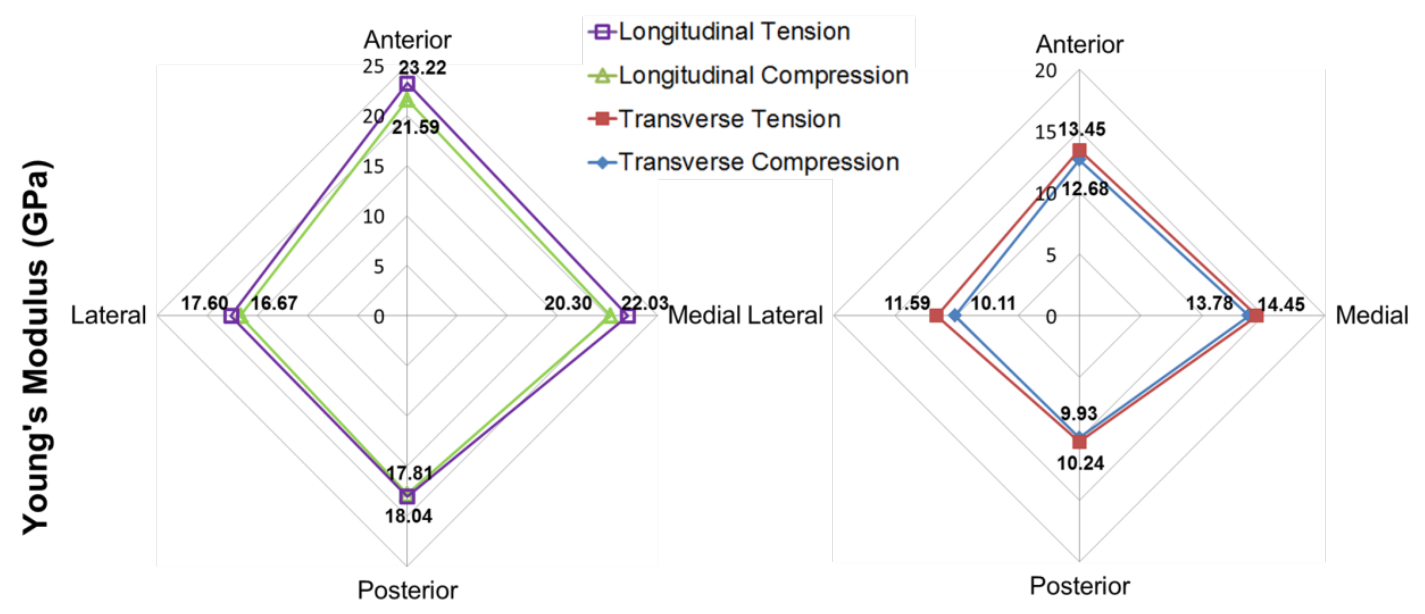

Fig. 8 Variability of Young's modulus across cortices for longitudinal (a) and transverse (b) direction

Table 4 Two-way ANOVA analysis result at significant level of 0.05 using Tukey HSD multiple comparison with pairwise comparison between factors (Long and Tran denote longitudinal and transverse, respectively)

\begin{tabular}{c|c|c|c}
\hline & Anterior & Medial & Posterior \\
\hline
\end{tabular}




\begin{tabular}{|c|c|c|c|c|c|c|c|}
\hline & & Medial & Posterior & Lateral & Posterior & \multicolumn{2}{|c|}{ Lateral } \\
\hline \multicolumn{8}{|c|}{ Factor A (Between cortices) } \\
\hline \multirow{2}{*}{\multicolumn{2}{|c|}{$\begin{array}{l}\text { Long } \\
\text { Tran }\end{array}$}} & 0.487 & $2 E-05$ & 0.002 & $5 E-07$ & $1 E-04$ & 0.798 \\
\hline & & 0.506 & 0.001 & $8 E-06$ & 0.022 & $3 E-04$ & 0.738 \\
\hline \multicolumn{8}{|c|}{ Factor A within Factor B (Between cortices) } \\
\hline \multirow{4}{*}{$\begin{array}{l}\text { Long } \\
\text { Tran }\end{array}$} & Comp & 0.743 & 0.029 & 0.228 & 0.003 & 0.038 & 0.806 \\
\hline & Ten & 0.522 & $4 E-4$ & 0.018 & $2 E-4$ & 0.008 & 0.987 \\
\hline & Comp & 0.672 & 0.043 & 0.003 & 0.064 & 0.005 & 0.998 \\
\hline & Ten & 0.562 & 0.036 & 0.001 & 0.365 & 0.027 & 0.636 \\
\hline & & \multicolumn{3}{|c|}{ Longitudinal } & \multicolumn{3}{|c|}{ Transverse } \\
\hline \multicolumn{8}{|c|}{ Factor B (Between loading modes) } \\
\hline & & \multicolumn{3}{|c|}{0.048} & \multicolumn{3}{|c|}{0.1} \\
\hline \multicolumn{8}{|c|}{ Factor B within Factor A (Between loading modes) } \\
\hline \multirow{4}{*}{\multicolumn{2}{|c|}{$\begin{array}{c}\text { Anterior } \\
\text { Medial } \\
\text { Posterior } \\
\text { Lateral }\end{array}$}} & \multirow{2}{*}{\multicolumn{3}{|c|}{$\begin{array}{l}0.12 \\
0.10\end{array}$}} & \multirow{2}{*}{\multicolumn{3}{|c|}{$\begin{array}{l}0.44 \\
0.51\end{array}$}} \\
\hline & & \multirow{2}{*}{\multicolumn{3}{|c|}{$\begin{array}{l}0.10 \\
0.82\end{array}$}} & & & \\
\hline & & & & & \multicolumn{3}{|c|}{$\begin{array}{l}0.51 \\
0.76\end{array}$} \\
\hline & & \multicolumn{3}{|c|}{0.36} & \multicolumn{3}{|c|}{0.15} \\
\hline
\end{tabular}

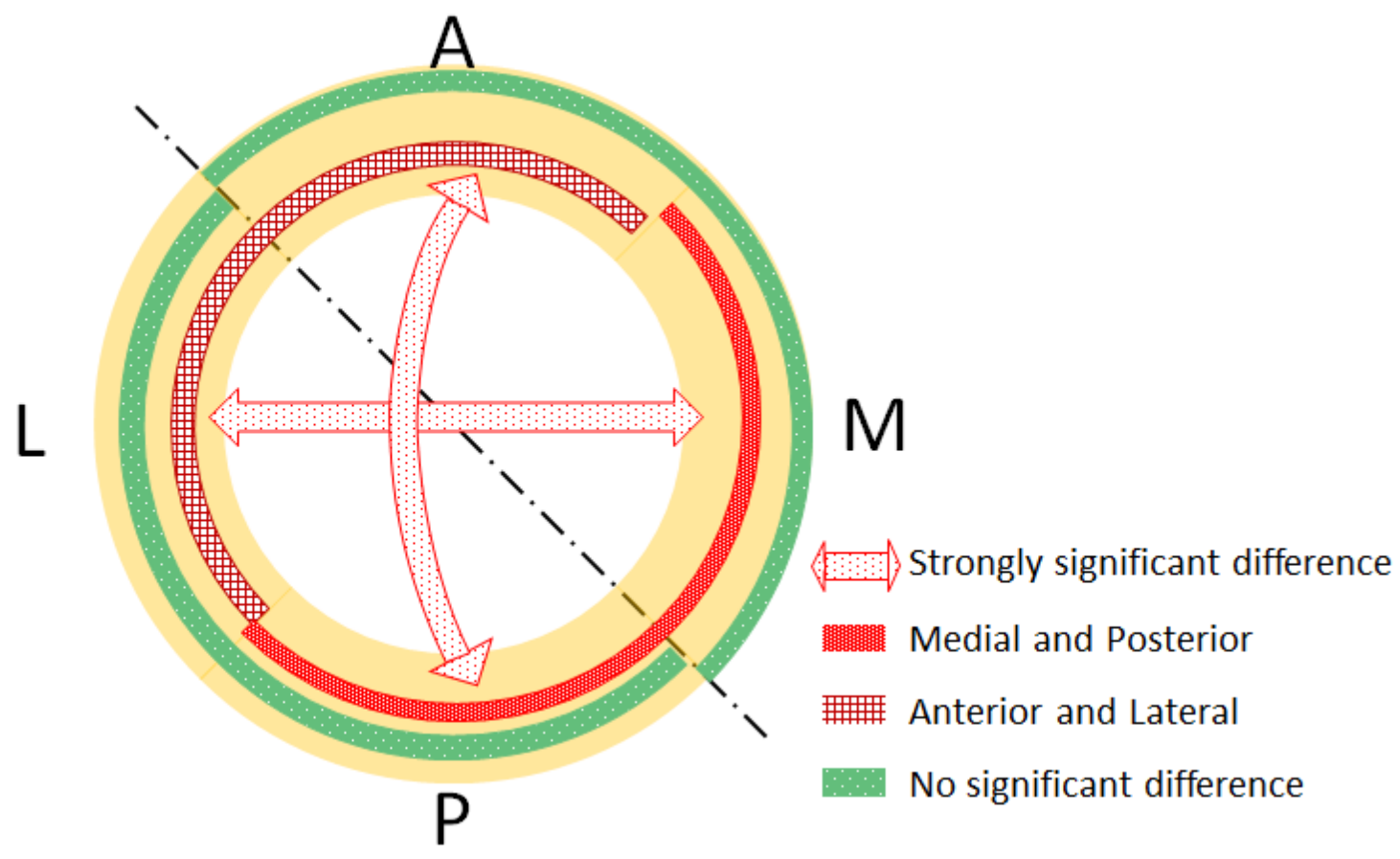

Fig. 9 Schematic of significant differences between quadrants (A, M, P and L represent the anterior, medial, posterior and lateral, respectively)

Although, a significant difference was found for the longitudinal direction within factor $B(p=0.048)$, to state that there is a significant difference between the loading modes may not be sensible. Firstly, the p value was just under the critical value of 
0.05. Secondly, an opposite result was observed for the transverse direction. Last but not least, pairwise comparisons between each quadrant also provided the contrasting results (Table 4).

The results of ANOVA analysis for yield stress, yield strain and ultimate strain showed no significant difference between cortices. Still, for ultimate stress, the significant difference only existed for the opposite cortices $(\mathrm{p}=0.003)$. This result implies that the post-yield behavior does not have a stable correlation with the variation of the microstructure. This could be due to the complexity and additonal statistical variables induced by randomized microstructure and various damage mechanisms (Li et al., 2012a and b) of cortical bone, not accounted for in this statistical analysis.

\subsection{Microstructure analysis}

The results from the optical microscopic analysis confirmed regional differences between different quadrants. Generally, the anterior quadrant is dominated by plexiform bone (over 50\%) and posterior quadrant has more osteonal bone (over $50 \%$ ). Medial and lateral quadrants are the transition sections between the two. This transition could also be evidenced by the relatively large standard deviation for porosity for these two quadrants, $\pm 2.21 \%$ and $\pm 3.94 \%$, respectively (Table 5). Within each quadrant, plexiform bone is usually located at the outer surface and then there is a transition into a mixture of osteonal and interstitial bone with a gradual increase of osteonal structure throughout the thickness (Fig. 10).

The results of optical microstructure analysis are listed in Table 5. As expected, the standard deviations of each constituent are large as the microstructure changes considerably within and between cortices. Substantial variations were also observed from upper to lower mid-diaphysis. The average fraction area of osteonal bone was measured between $13 \%$ and 54\%; interstitial bone ranged from $17 \%$ to $35 \%$; plexiform bone from $10 \%$ to $56 \%$ and porosity around 3\% to $9.51 \%$. Figure 10 demonstrates the color-coded microstructure image across the thickness of cortical bone for the medial quadrant. Figure 11 visually demonstrates the correlation of the Young's modulus and the volumetric fraction for four cortices.

Table 5 Microstructure analysis of average and standard deviation of volumetric fraction for each constituent for four cortices (Note: the maximum and minimum 
values instead of standard deviations were used for the volumetric fraction of plexiform for posterior and lateral cortices due to the large fluctuation of the data)

\begin{tabular}{|c|c|c|c|c|}
\hline Volumetric fraction & Osteonal (\%) & Interstitial (\%) & Plexiform (\%) & Porosity (\%) \\
\hline Anterior & $13.13( \pm 10.16)$ & $17.66 \quad( \pm 16.01)$ & $65.69 \quad( \pm 24.79)$ & $3.53 \quad( \pm 0.73)$ \\
\hline Medial & $16.40 \quad( \pm 14.49)$ & $25.51 \quad( \pm 19.56)$ & $53.40 \quad( \pm 34.52)$ & $4.69 \quad( \pm 2.21)$ \\
\hline Posterior & $54.01 \quad( \pm 17.58)$ & $30.40 \quad( \pm 16.96)$ & $\begin{array}{c}(25.6) \\
(0)\end{array}$ & $8.02 \quad( \pm 1.89)$ \\
\hline Lateral & $44.43 \quad( \pm 16.41)$ & $35.81 \quad( \pm 9.51)$ & $\begin{array}{cc}10.26 \quad(35.1) \\
(0)\end{array}$ & $9.51 \quad( \pm 3.94)$ \\
\hline
\end{tabular}

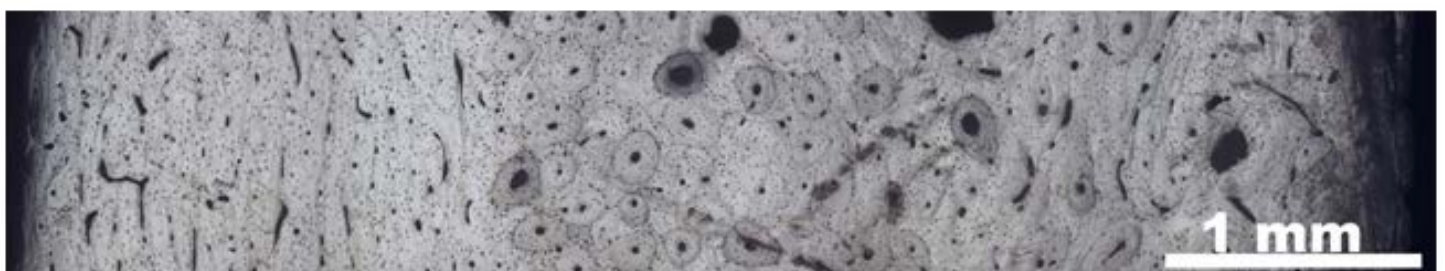

(a)

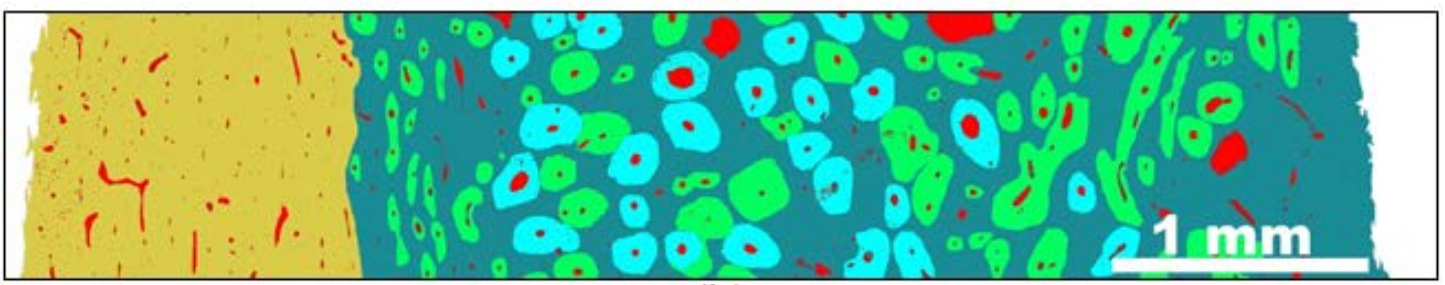

(b)

Fig. 7 (a) Microstructure transition across thickness at Medial quadrant; (b) colorcoded image for image analysis

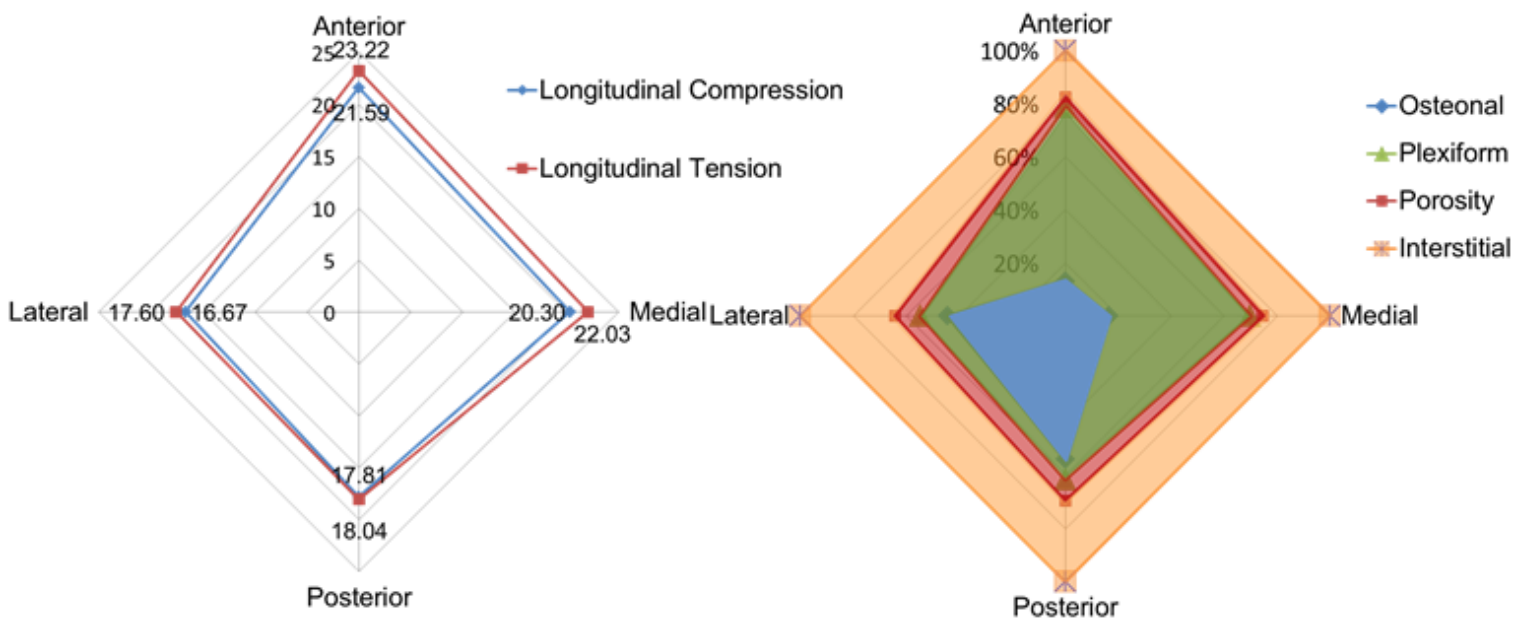

Fig. 8 Correlation of Young's modulus and volumetric fraction for four cortices 
The values of the effective Young's modulus calculated using Equation (1) are compared with our experimental results in Table 6. Comparing both the longitudinal and transverse Young's moduli for four anatomic quadrants, the theoretical predictions closely agree with the experimental results. A larger error for the transverse direction could be due to the fact that the volumetric fractions were measured at the surface parallel to the longitudinal loading plane, and may not be the same for the transverse loading plane.

Table 6 Comparison between theoretical prediction of effective elastic moduli and experimental data ( $\mathrm{L}$ and $\mathrm{T}$ denote longitudinal and transverse, respectively).

Experimental data are based on average for compression and tension specimens

\begin{tabular}{ccccc}
\hline \multirow{2}{*}{ Young's modulus (GPa) } & $\begin{array}{c}\text { Theoretical } \\
\text { prediction }\end{array}$ & $\begin{array}{c}\text { Experimental } \\
\text { data }\end{array}$ & $\begin{array}{c}\text { Error } \\
\text { (\%) }\end{array}$ \\
\hline \multirow{2}{*}{ Anterior } & $\mathrm{L}$ & 22.29 & 22.40 & 0.52 \\
& $\mathrm{~T}$ & 13.00 & 13.06 & 0.52 \\
\multirow{2}{*}{ Medial } & $\mathrm{L}$ & 21.02 & 21.17 & 0.71 \\
& $\mathrm{~T}$ & 12.19 & 14.11 & 13.6 \\
\multirow{2}{*}{ Posterior } & $\mathrm{L}$ & 17.04 & 17.93 & 4.94 \\
& $\mathrm{~T}$ & 9.67 & 10.08 & 4.13 \\
\multirow{2}{*}{ Lateral } & $\mathrm{L}$ & 16.15 & 17.14 & 5.75 \\
& $\mathrm{~T}$ & 9.17 & 10.85 & 15.5 \\
\hline
\end{tabular}

\section{Discussion}

The obtained experimental results for the mechanical properties in this study are well correlated with the literature data e.g. (Reilly and Burstein, 1975). Still, they differ from (Mercer et al., 2006), who reported a failure strain of $2.4 \%$ in tension and $1.6 \%$ in compression measured by strain gauge during the four-point bending test. This difference could possibly ascribe to the difference induced by various mechanical testing methods or testing conditions (Rho et al., 1998). Other factors such as the dissimilarity of species and differences in their age and gender can contribute to variability of the mechanical properties; still, quantification of these differences is beyond the scope of this study and, therefore, not discussed here. The variability of the mechanical properties across different cortices is consistent with previous research (Abdel-Wahab et al., 2010). In summary, the anisotropic 
mechanical properties depend on both loading modes and orientations. When bone is loaded in its natural mode - along the longitudinal direction in compression, it offers the best load-bearing capacity both in terms of strength and toughness. Outside this natural zone, the mechanical performance of cortical bone reduces dramatically: only half of its highest stiffness and one fifth of its highest strength was demonstrated for tension in transverse direction. The slight but not significant variance that observed between the tension and compression elastic moduli could be explained as the closure of the porous spaces at compression, which leads to a softening effect on overall stiffness. The compliance of the testing rig also contributes more in compression than in tension as the maximum strength in compression was double of that in tension.

The distinct post-yield regions in tension and compression indicate complex damage and strain hardening effects acting in compression. With micro-crack initiated at low stress levels (O'Brien et al., 2003), damage could start well before the material yields. At the same time, stiffness reduction was suppressed at compressive conditions due to the closing of cracks (Kasiri et al., 2010). The overall result is a mixture of progressive damage process and local strain hardening in compression. Different damage mechanisms associated with tension and compression also affect the load-bearing capacity. In tension, a diffused microcrack mechanism was reported in the literature, while linear, cross-hatched microcracks were reported in the region under compression (Boyce et al., 1998). With more energy dissipated in cross-hatch damage than in diffuse damage (Nyman et al., 2009), more energy is needed in compression to generate new crack surfaces than in tension. That, in turn, requires a larger area underneath the stress-strain curve, and consequently, results in higher stress and strain values in compression.

As a result of random, heterogeneous nature of cortical bone's microstructure, the progressive damage behavior is less predictable in compression. The magnitude of stress reduction is inversely correlated to the amount of on-site damage and the interaction of friction as well as strain hardening. The Weibull analysis reveals the 
distinctive failure regions where, the longitudinal compressive specimens have the highest reliability both in terms of ultimate stress and ultimate strain.

The anisotropy induced by changing orientations coincides with those reported in (Abdel-Wahab et al., 2010) and can be explained by the anisotropic alignment within the hierarchic layout of the material. From micro to nano scale, individual constituents such as collagen fibers, mineral plate, osteons and lamellae structures are aligned predominantly parallel to the longitudinal axial (Rho et al., 1998) resulting in the highest strength in this direction.

The variability of the elastic modulus across different quadrants is largely related to the changeable microstructure, and this result was also corroborated by the previous research (Abdel-Wahab et al., 2010). Significant differences were found for various quadrants but not for different loading modes. The statistical analysis results revealed a possible histological linkage between the anterior to medial quadrant and the medial to lateral quadrants. Skedros and co-authors (Skedros et al., 2006; Su et al., 1999) tested the calcaneus of a mule deer using in vitro loading method, and their results concluded that anterior and medial quadrants were predominately exposed to longitudinal compressive loading, while posterior and lateral quadrants were subjected to longitudinal tensile loading. The positions of neutral loading axis reported in the same study were similar to that shown in Fig. 9. Although the analysis for in vitro loading conditions is a more complicated process, which includes the interaction between tendon and muscle force as well as central gravity etc., and is beyond the scope of this study, results from our analysis as well as in (Skedros et al., 2006; Su et al., 1999) demonstrate a possible linkage between the bone mechanical properties and mechanical-induced bone adaptation. However, it is too early to draw the conclusion from these results. Riggs et al. (1993b) analyzed the collagen fiber orientation of the equine radius and revealed the contrasting relation between four quadrants. Potentially, this implies that the variation of material properties or microstructure may differ between species or bone types.

Microstructure analysis produced details of the microstructure transition between and within different quadrants. The anterior quadrant was dominated by plexiform 
bone and had the smallest porosity area, while the posterior quadrant is extensively remodeled, with the largest volume fraction of secondary osteons. The medial and lateral quadrants are transitions from the anterior to posterior quadrant. For each individual constituent, porosity (Currey, 1988a; Sevostianov and Kachanov, 2000) and secondary osteons (Saha and Hayes, 1977) were reported to be inversely correlated with the Young's modulus, which corroborates to our finding. The result of theoretical predictions of the effective elastic modulus proved to be accurate. The overall elastic behavior of cortical bone is strictly dependent of the microstructure of all constituents (Hamed et al., 2010); hence, over simplification can cause inaccurate results (Novitskaya et al., 2011).

\section{Conclusion}

The variability and anisotropy of mechanical behaviors of cortices of cortical bone were observed and compared in this study both for different loading modes and orientations. The deformation and damage behaviors differ, and they depend on the type of loading applied. A compressive longitudinal mode results in the best loadbearing capacity, whereas tensile transverse loading provides very poor results. Stress reduction after the damage onsite is less predictable in compression due to the involvement of various damage mechanisms. The random and heterogeneous arrangement of the microstructure contributes to a wide range of mechanical properties observed in this study as well as in the literature. Using powerful statistical analysis tools, the found correlations between the variation of elastic modulus and histological quadrants unfold a possible linkage between mechanical properties and the mechanically induced bone adaption. Beyond the linear-elastic working conditions, cortical bone demonstrates fewer correlatives because of the involvement of damage mechanisms, which bring uncertainty into the overall stress-strain relationship. The microstructure analysis again confirmed this transition at microscopic level between anatomic quadrants. The theoretical calculations of the effective Young's modulus accurately reproduced our experimental results, which provide another evidence of the strong relationship between microstructure and elastic modulus. 


\section{Acknowledgement}

The authors are grateful to the EPSRC UK (grant EP/G04886/1) for financial support of these studies.

\section{References}

Abdel-Wahab, A. A., Alam, K., Silberschmidt, V. V. 2010. Analysis of anisotropic viscoelastoplastic properties of cortical bone tissues. J. Mech. Behav. Biomed. Mater. 4, 807-820.

Ashman, R. B., Cowin, S. C., Van Buskirk, W. C., Rice, J. C. 1984. A continuous wave technique for the measurement of the elastic properties of cortical bone. J. Biomech. 17, 349-361.

Bonfield, W., Clark, E. A. 1973. Elastic deformation of compact bone. J. Mater. Sci. 8, 1590-1594.

Bonfield, W., Grynpas, M. D. 1977. Anisotropy of the young's modulus of bone. Nature 283, 106-107.

Boyce, T. M., Fyhrie, D. P., Glotkowski, M. C., Radin, E. L., Schaffler, M. B. 1998. Damage type and strain mode associations in human compact bone bending fatigue. J. Orthop. Res. 16, 322-329.

Budyn, E., Hoc, T. 2007. Multiple scale modeling of cortical bone fracture in tension using X-FEM. REMN. 16, 213-236.

Carter, D. R., Hayes, W. C. 1977. The compressive behavior of bone as a two-phase porous structure. J. Bone. Joint. Surg. Am. 59, 954.

Chen, P. Y., Stokes, A. G., McKittrick, J. 2009. Comparison of the structure and mechanical properties of bovine femur bone and antler of the north american elk (cervus elaphus canadensis). Acta. Biomater. 5, 693-706.

Currey, J. D. 1984. Comparative mechanical properties and histology of bone. Am. Zool. 24, 5-12. 
Currey, J. D. 1988a. The effect of porosity and mineral content on the young's modulus of elasticity of compact bone. J. Biomech. 21, 131-139.

Currey, J. D. 1988b. The effects of drying and re-wetting on some mechanical properties of cortical bone. J. Biomech. 21, 439-441.

Currey, J. D. 2004. Incompatible mechanical properties in compact bone. J. Theor. Biol. 231, 569-580.

Currey, J. D. 2011. The structure and mechanics of bone. J. Mater. Sci. 41, 41-54.

Fritsch, A., Hellmich, C. 2007. 'Universal'microstructural patterns in cortical and trabecular, extracellular and extravascular bone materials: Micromechanics-based prediction of anisotropic elasticity. J. Theor. Biol. 244, 597-620.

George, W. T., Vashishth, D. 2005. Damage mechanisms and failure modes of cortical bone under components of physiological loading. J. Orthop. Res. 23, 10471053.

Hamed, E., Lee, Y., Jasiuk, I. 2010. Multiscale modeling of elastic properties of cortical bone. Acta. Mech. 213, 131-154.

Kasiri, S., Reilly, G., Taylor, D. 2010. Wedge indentation fracture of cortical bone: Experimental data and predictions. J. Biomech. Eng. 132, 081009-1-6.

Kotha, S., Guzelsu, N. 2003. Tensile damage and its effects on cortical bone. J. Biomech. 36, 1683-1689.

Lai, Y. M., Qin, L., Hung, V. W. Y., Chan, K. M. 2005. Regional differences in cortical bone mineral density in the weight-bearing long bone shaft--a pQCT study. Bone. 36, 465-471.

Lawrence, K. J., Yoon, H. S., Lipson, S., Maharidge, R., Meunier, A., Christel, P. 1984. The effects of remodeling on the elastic properties of bone. Calcif. Tissue. Int. 36, 31-36.

Li, S., Abdel-Wahab, A. A., Silberschmidt, V. V. 2012a. Analysis of fracture processes in cortical bone tissue. Eng. Fract. Mech. http://dx.doi.org/10.1016/j.engfracmech.2012.11.020. 
Li, S., Demirci, E., Silberschmidt, V. V. 2012b. Analysis of deformation characteristics of cortical bone tissue. Solid State Phenom. 188, 118-123.

Martin, R. B., Burr, D. B., Sharkey, N. A. Skeletal tissue mechanics. New York, USA,: Springer Verlag, 1998.

Mercer, C., He, M. Y., Wang, R., Evans, A. G. 2006. Mechanisms governing the inelastic deformation of cortical bone and application to trabecular bone. Acta. Biomater. 2, 59-68.

Novitskaya, E., Chen, P. Y., Lee, S., Castro-Ceseña, A., Hirata, G., Lubarda, V. A., McKittrick, J. 2011. Anisotropy in the compressive mechanical properties of bovine cortical bone and the mineral and protein constituents. Acta. Biomater. 7, 31703177.

Nyman, J. S., Leng, H., Dong, X. N., Wang, X. 2009. Differences in the mechanical behavior of cortical bone between compression and tension when subjected to progressive loading. J. Mech. Behav. Biomed. Mater. 2, 613-619.

O'Brien, F. J., Taylor, D., Lee, T. C. 2003. Microcrack accumulation at different intervals during fatigue testing of compact bone. J. Biomech. 36, 973-980.

O'Brien, F. J., Taylor, D., Lee, T. C. 2005. The effect of bone microstructure on the initiation and growth of microcracks. J. Orthop. Res. 23, 475-480.

Reilly, D. T., Burstein, A. H. 1974. The mechanical properties of cortical bone. J. Bone Joint. Surg. 56, 1001.

Reilly, D. T., Burstein, A. H. 1975. The elastic and ultimate properties of compact bone tissue. J. Biomech. 8, 393-396, IN9-IN11, 397-405.

Rho, J. Y., Kuhn-Spearing, L., Zioupos, P. 1998. Mechanical properties and the hierarchical structure of bone. Med. Eng. Phys. 20, 92-102.

Rho, J. Y., Pharr, G. M. 1999. Effects of drying on the mechanical properties of bovine femur measured by nanoindentation. J. Mater. Sci. Mater. Med 10, 485-488.

Rho, J. Y., Tsui, T. Y., Pharr, G. M. 1997. Elastic properties of human cortical and trabecular lamellar bone measured by nanoindentation. Biomater. 18, 1325-1330. 
Riggs, C. M., Lanyon, L. E., Boyde, A. 1993a. Functional associations between collagen fibre orientation and locomotor strain direction in cortical bone of the equine radius. Anat. Embryol. 187, 231-238.

Riggs, C. M., Vaughan, L. C., Evans, G. P., Lanyon, L. E., Boyde, A. 1993 b. Mechanical implications of collagen fibre orientation in cortical bone of the equine radius. Anat. Embryol. 187, 239-248.

Ritchie, R. O., Kinney, J. H., Kruzic, J. J., Nalla, R. K. 2005. A fracture mechanics and mechanistic approach to the failure of cortical bone. Fatigue. Fract. Eng. M. 28, 345-371.

Saha, S., Hayes, W. C. 1977. Relations between tensile impact properties and microstructure of compact bone. Calcif. Tissue. Int. 24, 65-72.

Sevostianov, I., Kachanov, M. 2000. Impact of the porous microstructure on the overall elastic properties of the osteonal cortical bone. J. Biomech. 33, 881-888.

Skedros, J. G., Mason, M. W., Bloebaum, R. D. 1994. Differences in osteonal micromorphology between tensile and compressive cortices of a bending skeletal system: Indications of potential strain-specific differences in bone microstructure. Anat. Rec. 239, 405-413.

Skedros, J. G., Sorenson, S. M., Takano, Y., Turner, C. H. 2006. Dissociation of mineral and collagen orientations may differentially adapt compact bone for regional loading environments: Results from acoustic velocity measurements in deer calcanei. Bone. 39, 143-151.

Skedros, J. G., Su, S. C., Bloebaum, R. D. 1997. Biomechanical implications of mineral content and microstructural variations in cortical bone of horse, elk, and sheep calcanei. Anat. Rec. 249, 297-316.

Su, S. C., Skedros, J. G., Bachus, K. N., Bloebaum, R. D. 1999. Loading conditions and cortical bone construction of an artiodactyl calcaneus. J. Exp. Biol. 202, 32393254.

Weibull, W. 1951. A statistical distribution function of wide applicability. J. Appl. Mech-T. ASME. 18, 293-297. 
Zioupos, P., Currey, J. D., Mirza, M. S., Barton, D. C. 1995. Experimentally determined microcracking around a circular hole in a flat plate of bone: Comparison with predicted stresses. Philos. T. Roy. Soc. B 347, 383-396. 